\title{
Study on the Implementation of Enterprise Strategy Based on the Performance Excellence Model
}

\author{
Wei Zhu ${ }^{a}$ and Yaxuan Sun ${ }^{b}$ \\ School of Management, China University of Mining and Technology (Beijing), Beijing 100083, China. \\ a17701020338@163.com, byaxuan_sun@163.com
}

Keywords: Performance Excellence Model, Scientific strategic management system, Strategic management.

\begin{abstract}
In recent years, as a major evaluation tool for enterprise quality management, the excellent performance model plays an increasingly important role in improving the management level of Chinese enterprises, and strategic management plays a guiding role in enterprise development. In order to improve our strategic management level and the strategic management system .This paper summarizes and analyzes the key aspects of strategic management based on the framework of performance excellent evaluation.
\end{abstract}

\section{Introduction}

With the rapid changes in the economic environment of the global market, the enterprises development is facing competition. In order to speed up the pace of enterprise development and strengthen efficiency of organization capabilities, it is necessary to formulate a reasonable and implement enterprise strategy for achieving a successful completion of strategic objectives. Therefore, it becomes the focus of enterprise development nowadays that how to formulate reasonable enterprise strategic goals and use reasonable indicators to evaluate the implementation of the strategy.

At present, there are many methods for evaluating the implementation of strategies at home and abroad. Jaunting Li introduced project management methods into the strategic management of enterprises, and explored the ideas for the implementation of enterprise strategies by analyzing the relationship between them [1]. Xenon Li elaborated on the principle of using the Balanced Scorecard, and offered advice on the implementation of the Balanced Scorecard in the process of enterprise strategic management [2]. Tianna Zhang etc. combined analytic hierarchy process and grey correlation analysis method to quantitatively evaluate the synergy effect of enterprise strategy implementation [3]. Changing Li etc. divided the enterprise strategy into a number of stages based on the project life, and then proposed an overall implementation strategy based on the implementation of each stages [4].

The paper analyzes the implementation of enterprise strategies based on the Performance Excellence Model. Examining the strategic management aspects from the perspective of the Performance Excellence Model, then elaborating on various aspects of strategy formulation, strategy analysis and selection, strategy planning and deployment, strategy controlling and forecasting, and then identifying key factors that influence the formulation and management of enterprise strategy. Finally analyzing the problems existed in the enterprise and proposing specific solutions to improve the strategic management level of the enterprise.

\section{Introduction of the Performance Excellence Model}

In 2016, Premier Keqiang Li pointed out at the 2nd China Quality Awards Conference that quality development is the basis of strong power, the foundation of industry and the need of transformation. The pursuit of excellent quality should become the value orientation and spirit of the entire society and the nation. The Performance Excellence Model, as a tool of the China Quality Award and the evaluation of quality awards by provinces and cities, is very significant to the development of quality 
in China. As the evaluation standard of the Baldrige National Quality Award in the United States, has became a comprehensive performance management model that can promote the level of enterprise management. It has been promulgated and implemented in more than 90 countries and regions around the world, and the core concept of customer-oriented, focusing on results, pursuing excellence in enterprise management concepts. As a reference standard for self-evaluation and quality award assessment, the Performance Excellence Model has been constantly revised in light of environment changes and the development of the times. The latest versions are GB/T 19580-2012 Criteria for Performance Excellence and GB/Z 19579-2012 Guidelines for the criteria of performance excellence, in which the framework for excellence performance evaluation guidelines (as shown in Figure 1), graphically depict the relationship and logic between the seven categories in the Excellence Performance Evaluation Guidelines. The "leadership triangle" consisting of "4.1 Leadership", "4.2 Strategy", and "4.3 Customers and Market" reflect their driving role in the performance management system; "4.4 Resources" and "4.5 Process Management" and "4.7 Results" three parts constitute "Triangle of Resources, Process and Results", which show that "Resources" and "Process Management" are used to achieve excellent results, and "4.6 Measurement, Analysis and Improvement" is the basis of performance management system. The " 4.6 " is a chain linking two triangles, which can effectively promote the improvement and innovation of enterprises and play a vital role in improving the performance and competitiveness of enterprises.

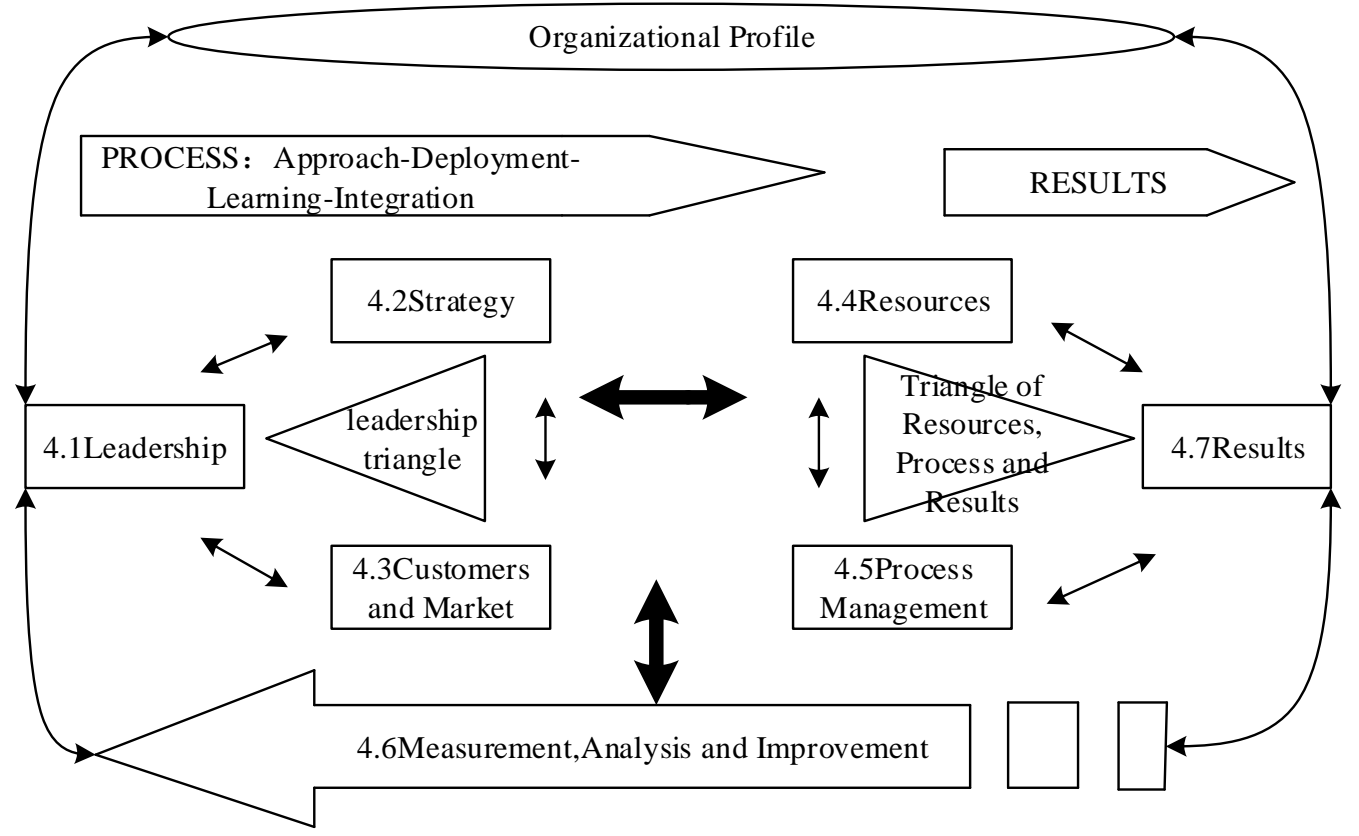

Figure 1 Framework for performance excellence evaluation

\section{The Key Links of Strategic Management from the Perspective of the Performance Excellence Model}

Strategy plays a guiding role in the development of the enterprise and is an integral part of the enterprise development. Although many companies have formulated strategic plans, there are still many problems with strategic management. This paper is based on the specific requirements for strategic management in the " 4.2 Strategy" of Criteria for Performance Excellence. The strategic management should be a complete closed-loop that consists of "strategic formulation-strategic analysis and selection - strategic planning and deployment - strategic control ". By sorting out the evaluation requirements of the strategic part in Criteria for Performance Excellence, this paper summed up the main concerns of the strategic management major aspects as follows: 
(1) Strategic formulation process: Establishing a scientific strategy development process, sort out major steps, and implement key players; Dividing strategic intervals and ensure coordination between long and short-term plans.

(2) Strategic analysis and selection: Comprehensively collecting the key factors of economic situation, competitive environment, customer and market demand, industry influence, etc.; Using scientific methods (PEST, Porter's Five Forces Model, key success factors, etc.) to analyze the macro environment, industry environment, internal environment, etc.; Formulating overall corporation strategy and strategic objectives, elaborating timetables and key quantitative indicators for strategic objectives.

(3)Strategic planning and deployment: Formulating and deploying implementation plans for achieving strategic objectives, then adjusting the implementation plans in accordance with environment changes; Implementing the long-term and short-term plan of the enterprise, acquiring and configuring various resources to ensure the realization of the plan.

(4) Strategic controlling: Establishing a key performance indicators system that can monitor the progress of implementation plans; Strictly controlling the implementation of the strategy, analyzing and comparing the results with the implementation plan in a timely manner to evaluate the strategic performance.

(5) Strategic performance prediction: Using scientific forecasting methods to predict the outcome of key performance indicators during the long and short-term planning period; Using the forecast results to guide the enterprise strategy formulation, analysis and selection, planning and deployment, control, etc.

\section{Measures and Recommendations for Enhancing Strategic Management}

Enterprises can systematically learn Excellence Performance Evaluation Standards, and gradually introduce the "4.2 Strategy" module into the enterprise that combine industry characteristics and enterprise reality. Enterprises should establish a system suitable for enterprise strategic management, and comprehensively evaluate the level of enterprise strategic management. Firstly, Enterprises need to understand and learn strategic management methods and apply them to strategy formulation; secondly, enterprises need establish strategic adjustment mechanisms and adjust when internal and external environments undergo major changes; tertiary enterprises need refine strategic objectives and develop resource allocation plans to ensure that basic resources can adapt the implementation of the overall strategy. The establishment of a strategic forecasting and monitoring system, regular analysis, in order to grasp the implementation of the strategy to facilitate the enterprise's overall control, improve the level of strategic management.

\section{References}

[1]. Jaunting Li. Implement enterprise strategy development based on enterprise project management model [J]. Science and Technology Management Research, 2009 29(09):437-439.

[2]. Xenon Li. Study on the application of the Balanced Score Card in the Enterprise Strategic Management [J]. Management Observation, 2013, (19):17-19.

[3]. Tianna Zhang, Hong Liang Cao, Wending Ma. Research on the Synergy Effect Appraisal of Adaptive Enterprise Strategy Implementation Based on BSC Theory [J]. Journal of University of Science and Technology Beijing (Social Sciences Edition) 2016, 26 (01):37-43.

[4]. Changing Li. Study on corporate strategy implementation based on project life-cycle [D]. Ocean University of China, 2010. 